\title{
Inactivation of Caspase-1 in Rodent Brain: A Novel Anticonvulsive Strategy
}

\author{
*Teresa Ravizza, †Sian-Marie Lucas, *Silvia Balosso, $\ddagger$ Liliana Bernardino, $\S$ George Ku, \\ *Francesco Noé, †Joao Malva, §John C. R. Randle, †Stuart Allan, and *Annamaria Vezzani \\ *Department of Neuroscience, Mario Negri Institute for Pharmacological Research, Milan, Italy; $\dagger$ Faculty of Life Sciences, \\ University of Manchester, Manchester, United Kingdom; $\ddagger$ Center for Neuroscience and Cell Biology, Institute of Biochemistry, \\ University of Coimbra, Portugal; and §Vertex Pharmaceuticals, Inc., Cambridge, Massachusetts, U.S.A.
}

\begin{abstract}
Summary: Purpose: Cytokines and related inflammatory mediators are rapidly synthesized in the brain during seizures. We previously found that intracerebral administration of interleukin1 (IL-1)- $\beta$ has proconvulsant effects, whereas its endogenous receptor antagonist (IL-1Ra) mediates potent anticonvulsant actions in various models of limbic seizures. In this study, we investigated whether seizures can be effectively inhibited by blocking the brain production of IL- $1 \beta$, by using selective inhibitors of interleukin-converting enzyme (ICE/caspase-1) or through caspase-1 gene deletion.

Methods: Caspase-1 was selectively blocked by using pralnacasan or VX-765. IL- $1 \beta$ release was induced in mouse organotypic hippocampal slice cultures by proinflammatory stimuli [lipopolysaccaride (LPS) + adenosine triphosphate (ATP)] and measured with enzyme-linked immunosorbent assay (ELISA). IL- $1 \beta$ production during seizures was measured in the rat hip-
\end{abstract}

pocampus by Western blot. Seizures were induced in freely moving mice and rats by intrahippocampal injection of kainic acid and recorded by EEG analysis.

Results: Caspase- 1 inhibition reduced the release of IL- $1 \beta$ in organotypic slices exposed to LPS +ATP. Administration of pralnacasan (intracerebroventricular, $50 \mu \mathrm{g}$ ) or VX-765 (intraperitoneal, $25-200 \mathrm{mg} / \mathrm{kg}$ ) to rats blocked seizure-induced production of IL- $1 \beta$ in the hippocampus, and resulted in a twofold delay in seizure onset and 50\% reduction in seizure duration. Mice with caspase- 1 gene deletion showed a $70 \%$ reduction in seizures and an approximate fourfold delay in their onset.

Conclusions: Inhibition of caspase-1 represents an effective and novel anticonvulsive strategy, which acts by selectively reducing the brain availability of IL- $1 \beta$. Key Words: Cytokines-Epilepsy-Inflammation-Interleukin$1 \beta$-Glia-Hippocampus.
Inflammatory mediators are rapidly induced in rodent brain both in glia and in neurons during seizures (1-7). In particular, intracerebral application of intereukin- $1 \beta$ (IL$1 \beta$ ) prolongs the duration of electrographic (EEG) and behavioral seizures in rodents $(3,6)$. Conversely, IL-1Ra, a naturally occurring antagonist of IL- $1 \beta(8)$, mediates powerful anticonvulsant effects $(4,6)$, and mice overexpressing IL-1Ra in astrocytes show a dramatically reduced susceptibility to seizures $(6,9)$. Recently, the threshold to seizure induction in experimental models of febrile convulsions, was shown to be decreased by intracerebral IL- $1 \beta$ injection and raised in IL-1 receptor-deficient mice or after delivery of IL-1Ra $(10,11)$. These findings indicate that an increase in IL-1 $\beta$ levels in the brain, as occurs during seizures, has proconvulsant effects.

\footnotetext{
Accepted February 17, 2006.

Address correspondence and reprint requests to Dr. A. Vezzani at Laboratory of Experimental Neurology, Department of Neuroscience, Mario Negri Inst for Pharmacol Res, Via Eritrea 62, 20157 Milano, Italy. E-mail: vezzani@marionegri.it

The first two authors contributed equally to this work.

doi: 10.1111/j.1528-1167.2006.00590.x
}

This evidence prompted us to study whether preventing the brain production of IL- $1 \beta$ during seizures results in significant anticonvulsive effects. This goal was achieved by using selective inhibitors or gene deletion of caspase1 (12-14), the key enzyme specifically involved in the production of the releasable and biologically active form of IL- $1 \beta$.

\section{MATERIALS AND METHODS}

\section{Experimental animals}

Animals were housed at a constant temperature $\left(23^{\circ} \mathrm{C}\right)$ and relative humidity $(60 \%)$ with free access to food and water and a fixed 12-h light/dark cycle. Procedures involving animals and their care were conducted in conformity with the institutional guidelines that are in compliance with national (D.L.n.116, G.U., suppl.40, Feb. 18, 1992; UK legislation under the 1986 Animals Scientific Procedures Act) and international laws and policies (EEC Council Directive 86/609, OJ L 358, 1, Dec.12, 1987; Guide for the Care and Use of Laboratory Animals, U.S. National Research Council, 1996). 
Rats

Male Sprague-Dawley rats (250-280 g) were purchased from Charles River (Calco, Italy).

Mice

Caspase-1 knockout (KO) mice and their wild-type strain (C57BL6/SV129, 24 g) were kindly supplied by Dr. W. Wong (BASF Bioresearch Corporation, Worcester, MA, U.S.A.). Wild-type and KO animals were bred separately as homozygous groups from breeding couples of the same genetic background and at the time of the study were at generation 12 and 15 , respectively.

Caspase-1 KO mice have been extensively characterized previously: they develop normally and are healthy and fertile; they are highly resistant to the lethal effects of lipopolysaccharide (LPS), and their macrophages exhibit a severe defect in the production of mature IL-1 $\beta$ (15).

\section{Placement of cannula and electrodes for EEG recordings}

Rats

Rats were surgically implanted with cannulae and electrodes under stereotaxic guidance as previously described (3). In brief, rats were deeply anesthetized by using Equithesin (1\% phenobarbital and $4 \%$ chloral hydrate; $3 \mathrm{ml} / \mathrm{kg}$, intraperitoneally, i.p.). A ground lead was positioned over the nasal sinus, and two screw electrodes were placed bilaterally over the parietal cortex. Bipolar nichrome wireinsulated electrodes $(60 \mu \mathrm{m})$ were implanted bilaterally into the dorsal hippocampus (septal pole) at the following coordinates from bregma: $\mathrm{mm}$, nose bar $-2.5, \mathrm{AP}-3.5, \mathrm{~L}$ \pm 2.4 and 3.0 below dura mater. A 22 -gauge guide cannula was unilaterally positioned on top of the dura and glued to one of the depth electrodes for intrahippocampal injection of kainic acid. In some rats, an additional guide cannula was unilaterally positioned on top of the dura mater for intracerebroventricular (icv) injection of pralnacasan (in $\mathrm{mm}$ from bregma, nose bar -2.5 ; AP $-1 ; \mathrm{L}+1.5$ ). The electrodes were connected to a multipin socket (March Electronics, Bohemia, NY, U.S.A.) and, together with the injection cannula, were secured to the skull by acrylic dental cement.

\section{Mice}

Mice were anesthetized by using 5\% halothane (Concord Pharmaceuticals Ltd, Dunmow, Essex, U.K.) with oxygen as the carrier gas at a flow rate of $0.4 \mathrm{~L} / \mathrm{min}$. Anesthesia was maintained by inhalation of $1.5-2 \%$ halothane with oxygen. A ground lead was positioned over the nasal sinus. The stainless-steel recording electrode of an ETAF20 small-animal telemetry device (Data Sciences International, St. Paul, MN, U.S.A.) was unilaterally implanted into the septal pole of the dorsal hippocampus (in $\mathrm{mm}$ from bregma, nose bar $0 ; \mathrm{AP}-1.9 ; \mathrm{L}-1.5$ and 1.5 below dura mater), with the transmitter body being placed sub- cutaneously on the animal's flank. A 22-gauge injection cannula was attached to the depth electrode and positioned on top of the dura mater for the intrahippocampal injection of kainic acid. The experiments were performed $\geq 3$ days after surgery to allow the animals to recover.

\section{EEG recordings and injection of drugs}

The procedures for recording the EEG and intracerebral injection of drugs in freely moving rats or mice have been previously described $(3,6)$.

\section{Kainic acid}

Kainic acid (Sigma-Aldrich, St. Louis, MO, U.S.A.) was dissolved in $0.5 \mu \mathrm{l}$ phosphate-buffered saline (PBS, $\mathrm{pH} 7.4)$ and injected in the mouse (14 ng) or rat (40 ng) dorsal hippocampus unilaterally $(1 \mu \mathrm{l} / \mathrm{min})$, by using a needle protruding 1.5 or $3.0 \mathrm{~mm}$, respectively, from the guide cannula.

This dose of kainic acid was chosen to induce recurrent EEG epileptic activity composed of ictal episodes (EEG seizures) and spiking activity in $100 \%$ of animals without mortality.

\section{Pralnacasan and VX-765}

Pralnacasan (Vertex Pharmaceuticals, Inc., Cambridge, MA, U.S.A.) was dissolved in $20 \%$ cremophor ( $25 \mu \mathrm{g}$ in $4 \mu \mathrm{l}$, the maximal concentration soluble in the injected volume) and injected icv in rats or mice, $45 \mathrm{~min}$ and 10 min before intrahippocampal injection of kainic acid. In preliminary experiments, pralnacasan was also administered in a single dose $(12.5$ or $25 \mu \mathrm{g}$ in $4 \mu \mathrm{l}), 45 \mathrm{~min}$ before kainic acid. VX-765 (25, 50, $200 \mathrm{mg} / \mathrm{kg}$; Vertex Pharmaceuticals) was dissolved in $20 \%$ cremophor and injected ip in rats once a day for 3 consecutive days. On the fourth day, rats received VX-765, $45 \mathrm{~min}$ and $10 \mathrm{~min}$ before intrahippocampal injection of kainic acid. Respective controls were similarly injected with vehicle before kainic acid.

The correct positioning of the injection needle and electrodes was verified by Nissl staining of $40-\mu \mathrm{m}$ cryostat coronal brain sections in all the animals, $24 \mathrm{~h}$ after kainic acid injection (not shown). In mice, no evidence of neuronal cell loss was observed in any experimental condition; in rats treated with kainic acid, we observed the typical pattern of pyramidal cell loss restricted to CA3 area, as previously reported in detail $(3,16)$. The unspecific damage restricted to the insertion of injection needle and the electrode tracks was similar in control and experimental animals. All pharmacologic experiments were carried out between 9.00 a.m. and 1.00 p.m.

\section{Seizure assessment and quantification}

Rats

EEG seizures induced by intrahippocampal injection of kainic acid in rats have been extensively described 
(3). In brief, a 30-min recording was done before kainic acid injection to assess the basal EEG pattern. Recording was stopped after 180 min from kainate injection, a time at which seizure activity was absent for $\geq 30 \mathrm{~min}$ in all the animals. Ictal episodes were characterized by high-frequency and/or multispike complexes and/or highvoltage synchronized spikes simultaneously occurring in the injected hippocampus. Spiking activity was typically observed after seizures subsided (3). The EEG recording of each animal was analyzed visually by two independent investigators blinded to the treatments to detect any activity different from baseline. Seizure activity was quantified by counting the time to seizure onset (elapsed from kainic acid injection to the occurrence of the first EEG seizure) and the total number and duration of seizures (counted by summing the duration of every ictal episode during the EEG recording period) (3). Shortly after its administration, kainic acid induced stereotyped behaviors such as sniffing and gnawing. "Wet-dog shakes" were often observed shortly after kainate injection and during seizures.

Mice

EEG was acquired by remote telemetry. The signal from the recording depth electrode was transmitted by radiofrequency and captured by a receiver pad (Data Sciences) under the cage of each animal. This signal was relayed to a computer that sampled and recorded the analogue output by using Dataquest A.R.T. Analog (Data Sciences). The EEG patterns were recorded and visualized by using Datapac 2K2 (RUN Technologies, Laguna Hills, CA, U.S.A.). A baseline recording of $\geq 30$ minutes was acquired before drug treatments. Recording was stopped after 180 min from kainate injection, a time at which seizure activity was absent for $\geq 30 \mathrm{~min}$ in all the animals. Seizure activity was quantified as in the rat.

Western blot analysis

Different groups of rats ( $\mathrm{n}=3$ in each treatment group) were treated icv with pralnacasan or its vehicle given alone, or before intrahippocampal application of kainic acid (see earlier). Ninety minutes after the onset of EEG seizures, when pralnacasan effect on seizures was evident (see Results), experimental rats and their controls were decapitated. The injected hippocampi were dissected out at $4{ }^{\circ} \mathrm{C}$ and homogenized in $20 \mathrm{mM}$ Tris- $\mathrm{HCl}$ buffer (pH 7.4), containing $1 \mathrm{~m} M$ EDTA, $5 \mathrm{~m} M$ EGTA, $1 \mathrm{~m} M$ Na-vanadate, $2 \mu \mathrm{g} / \mu \mathrm{l}$ aprotinin, $1 \mu \mathrm{g} / \mu \mathrm{l}$ pepstatin, and $2 \mu \mathrm{g} / \mu 1$ leupeptin (30 $\mathrm{mg}$ tissue $/ 150 \mu \mathrm{l}$ homogenization buffer). Total proteins (150 $\mu \mathrm{g}$ per lane; Bio-Rad Protein Assay, Bio-Rad Labs, Munich, Germany) were separated by using sodium dodecylsulfate-polyacrylamide gel electrophoresis (SDS-PAGE), 10\% acrylamide, and each sample was run in duplicate. Proteins were transferred to Hybond nitrocellulose membranes by electroblotting. For immunoblotting, we used anti-rat IL-1 $\beta$ $(0.2 \mu \mathrm{g} / \mathrm{ml}$; Abcam Limited, Cambridgeshire, UK) or anti- mouse IL-18 (1:250, kindly provided by Dr. Dinarello) rabbit polyclonal antibodies. Immunoreactivity was visualized with enhanced chemiluminescence (ECL; Amersham, U.K.) by using peroxydase-conjugated goat antirabbit $\operatorname{IgG}(1: 2,000$; Sigma) as secondary antibodies. Densitometric analysis of immunoblots was done to quantify the changes in protein levels (AIS image analyzer; Imaging Research Inc., St. Catherines, Ontario, Canada) by using film exposures with maximal signals below the photographic saturation point. Optical density values in each sample were normalized by using the corresponding amount of $\alpha$-actin.

\section{Organotypic hippocampal slice cultures}

Hippocampal slice cultures were prepared from 7-dayold C57BL/6 mice (Charles River, Calco, Italy), according to the interface culture method (17) with some modifications (18). In brief, mice were killed by decapitation, the brains removed under sterile conditions, and the two hippocampi isolated and cut in transverse sections at $350 \mu \mathrm{m}$, using a McIlwain tissue chopper. Individual slices were placed in ice-cold Gey's balanced salt solution (GBSS; Biological Industries, Kibbuts Beit Haemek, Israel) supplemented with $25 \mathrm{mM}$ D-glucose (Merck, Germany); then they were placed on semiporous inserts membranes (6 slices on each membrane; Millipore Corp., Bedford, MA, U.S.A.) and transferred to 6-well culture trays (Corning Costar, Corning, NY, U.S.A.). Each membrane was immersed in a well containing $1 \mathrm{ml}$ culture medium composed of 50\% Opti-MEM, 25\% heat-inactivated horse serum, and 25\% Hank's balanced salt solution (HBSS) (Gibco BRL, Life Technologies Ltd., East Kilbride, Lanarkshire, Scotland, U.K.) and supplemented with 25 $\mathrm{m} M$ D-glucose. The cultures were incubated for 2 weeks with $5 \% \mathrm{CO}_{2}$ and $95 \%$ atmospheric air at $33^{\circ} \mathrm{C}$, and medium was changed twice a week; no antibiotics or antimitotics were used. On the day of the experiment, the culture medium was replaced with $1 \mathrm{ml}$ of chemically defined, serum-free Neurobasal medium with $1 \mathrm{~m} M$ Lglutamine and B27 supplement (Gibco BRL, Life Technologies Ltd).

Inflammatory stimuli were provided to organotypic slice cultures by preexposure to $10 \mathrm{ng} / \mathrm{ml}$ LPS (Escherichia coli serotype 055:B5; Sigma-Aldrich) for $3 \mathrm{~h}$ followed by $3 \mathrm{~h}$ coincubation with $1 \mathrm{~m} M$ ATP (SigmaAldrich). Previous evidence in human monocytes has shown that this protocol is required for inducing both the production and the release of the mature and biologically active form of IL-1 $\beta$ (19). To investigate the effect of caspase- 1 inhibitors on IL- $1 \beta$ production and subsequent release, slice cultures were preexposed to $0.1-10 \mu M$ pralnacasan or VX-765 for $2 \mathrm{~h}$ followed by coexposure with LPS for $3 \mathrm{~h}$ and LPS+ATP for a further $3 \mathrm{~h}$.

Organotypic slices not exposed to drugs were used as controls in every experiment. At the end of the 
experiments, tissue was pooled from six wells per experimental group, whereas the respective culture media were collected separately. All samples were stored at $-70^{\circ} \mathrm{C}$ until assayed by ELISA.

\section{ELISA}

Hippocampal slices were homogenized in $0.5 \mathrm{ml}$ icecold PBS (pH 7.4) containing a mixture of protease inhibitors (Roche Biochemical, Indianapolis, IL, U.S.A.), and 2\% of NP-40 (Sigma-Aldrich). The homogenates were centrifuged, and the supernatants were collected to measure IL- $1 \beta$ in the tissue.

IL- $1 \beta$ was measured in tissue and medium by using an ELISA kit (R\&D Systems, Minneapolis, MN, U.S.A.) containing an antibody selective against murine IL- $1 \beta$ that recognises both pro-IL- $1 \beta$ and the mature form of IL- $1 \beta$. The cytokine was measured according to manufacture's suggested protocol. Absorbance was read at $405 \mathrm{~nm}$. The detection limit was $<3 \mathrm{pg} / \mathrm{ml}$.

\section{Statistical analysis of data}

Data are represented as the mean $\pm \operatorname{SEM}$ ( $n$, number of individual samples). The effects of treatments were analyzed by two-way ANOVA followed by Fisher's test (for Western blot data), or by one-way ANOVA followed by Bonferroni's test (for organotypic cultures), or by one-way ANOVA followed by Tukey's test (for seizure analysis).

\section{RESULTS}

\section{Effects of caspase-1 inhibition on hippocampal IL-1 $\beta$}

\section{In vitro evidence}

It has been well established in cells of the immune system that LPS transcriptionally activates the IL- $1 \beta$ gene, resulting in enhanced production of IL- $1 \beta$. However, in the presence of a second stimulus such as ATP, caspase-1 is activated enzymatically to process pro-IL- $1 \beta$ to the mature and releasable IL-1 $\beta$ form (17 kDa) (19). We applied this protocol to mouse organotypic slice cultures to study the effects of caspase-1 inhibitors on the levels and release of IL- $1 \beta$ in hippocampal tissue.

Figure 1A and B shows that in organotypic hippocampal slice cultures, ATP is required for inducing a massive IL- $1 \beta$ release in the presence of LPS, as previously shown in human monocytes (19). Thus LPS alone increased IL$1 \beta$ release into the culture medium by $\sim 20$-fold $(\mathrm{p}<$ 0.01 ), whereas addition of ATP increased IL- $1 \beta$ release by $\sim 60$-fold compared with control untreated slices (panel $\mathrm{A}, \mathrm{p}<0.01$ vs. LPS alone). Two hours of preincubation with pralnacasan or VX-765 reduced in a dose-dependent manner the LPS+ATP-mediated release of IL- $1 \beta$ in the medium, reaching the levels observed when slices were incubated with LPS alone (panel A). Maximal 70\% inhibition was reached with a concentration of $1 \mu \mathrm{M}$ for both inhibitors. In the corresponding tissue extracts, LPS or the coexposure to LPS+ATP increased IL- $1 \beta$ levels to a similar extent $(\mathrm{p}<0.01$ vs. control slices; panel B) and pralnacasan or VX-765 did not affect LPS+ATP induced increase (panel B). The basal levels of IL- $1 \beta$ in the medium and in the tissue of control slices (not exposed to any treatment) were barely or not detectable and did not differ from those measured in the presence of ATP or pralnacasan and VX-765 alone. Although the ELISA method used to measure IL- $1 \beta$ in the tissue and in the medium does not permit distinguishing between pro-IL$1 \beta$ and the mature $17-\mathrm{kDa}$ cytokine, it is well established that $>90 \%$ of the releasable form of IL- $1 \beta$ consists of the $17-\mathrm{kDa}$ mature form, whereas the tissue content is mostly represented by pro-IL-1 $\beta$ (20).

\section{In vivo evidence}

Figure 1C and D shows the effect of pralnacasan on IL- $1 \beta$ levels induced in the rat hippocampus by seizures. Western blot analysis allowed distinguishing between the immature (pro-IL-1 $\beta, 30 \mathrm{kDa}$ ) and the mature and releasable form of IL-1 $\beta$ (17 kDa) (panel D). Seizures increased pro-IL- $1 \beta$ by $84 \%$ and the mature and releasable form of IL- $1 \beta$ by $20 \%$. Anticonvulsant doses of pralnacasan (see later) fully reversed the effect of kainic acidinduced seizures on the mature, releasable form of IL- $1 \beta$ ( $\mathrm{p}<0.01 \mathrm{vs}$. kainic acid), producing a total reduction of $50 \%$ below basal levels; consequently, pro-IL- $1 \beta$ was increased by $\sim 50 \%$ above the levels induced by seizures ( $\mathrm{p}<0.01$ vs. kainic acid). In control hippocampi, pralnacasan alone did not significantly affect pro-IL- $1 \beta$ while reducing mature IL- $1 \beta$ levels by $30 \%$ below basal values (panel C).

IL-18 immunoreactivity was also assessed by using Western blot analysis because this cytokine is a substrate of caspase-1 (21). However, no signal was detected in hippocampal homogenates either in basal conditions or during seizure activity. The lack of signal was not due to failure of the $\mathrm{Ab}$, because our $\mathrm{Ab}$ detected a specific band of $18 \mathrm{kDa}$ when tested against $1 \mu \mathrm{g}$ of human or rodent recombinant IL-18.

\section{Effects of caspase-1 inhibition on kainic acid-induced seizures}

\section{Pralnacasan}

Figure 2A shows the effect of two consecutive icv injections of pralnacasan on kainic acid-induced seizures in freely moving rats ( $25 \mu \mathrm{g}$ in $4 \mu \mathrm{l}$ given 45 and $10 \mathrm{~min}$ before kainic acid injection). Pralnacasan significantly delayed the time to seizure onset by twofold $(\mathrm{p}<0.01)$ and reduced the number of seizures by $20 \%(\mathrm{p}<0.01)$ and the total time spent in EEG seizures by $40 \%(\mathrm{p}<0.01)$. The average duration of seizures was also significantly reduced by $25 \%$ by pralnacasan (Vehicle, min, $1.6 \pm 0.09$; Pralnacasan, $1.2 \pm 0.07^{* *}, \mathrm{n}=8 ;{ }^{* *} \mathrm{p}<0.01$ by Student's $\mathrm{t}$ test). Pralnacasan did not affect seizures when given in a 

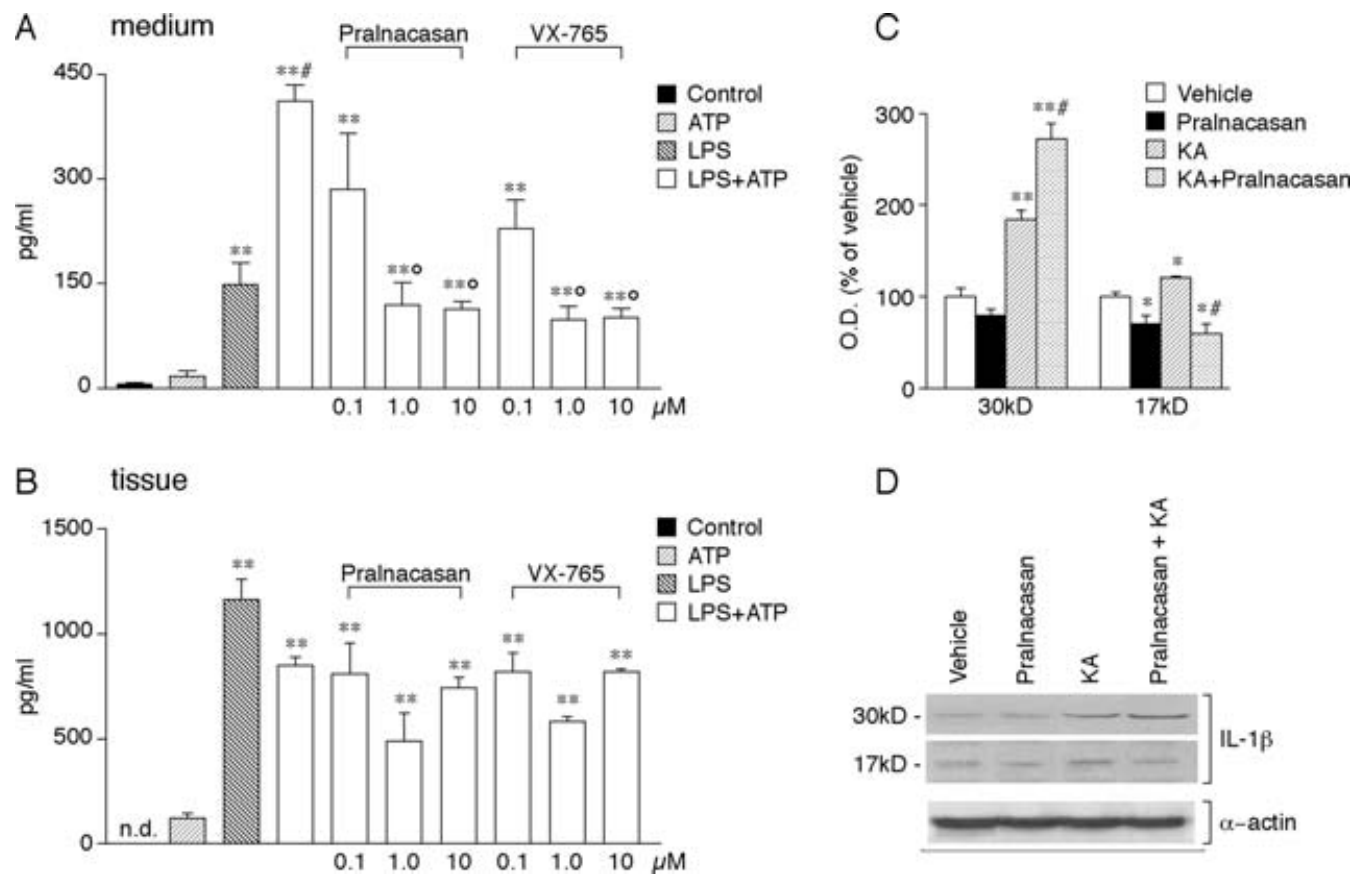

FIG. 1. Effects of pralnacasan and VX-765 on hippocampal IL-1 $\beta$ levels $\mathbf{A}$, B: Bargrams show IL-1 $\beta$ levels (mean \pm SEM, $n=6$ ) in mouse organotypic hippocampal slice culture media (A) and extracts (B), as assessed by ELISA. Slices were exposed for $3 \mathrm{~h}$ to $10 \mathrm{ng} / \mathrm{ml}$ lipopolysaccharide (LPS) followed by $3 \mathrm{~h}$ coincubation wih $1 \mathrm{mM}$ adenosine triphosphate (ATP), or they were incubated for $6 \mathrm{~h}$ with LPS alone. Slices were preincubated with pralnacasan or VX-765 $(0.1,1$, and $10 \mu \mathrm{M})$ for $2 \mathrm{~h}$ and for a subsequent $3 \mathrm{~h}$ with LPS, followed by $3 \mathrm{~h}$ exposure with LPS+ATP. Control cultures were not exposed to drugs. ${ }^{* *} p<0.01$ versus control; \#p $<0.01$ versus LPS; ${ }^{\circ} p<0.01$ versus LPS+ATP by one-way ANOVA followed by Bonferroni's test $(\mathrm{F}=45.4)$. C, D: Bargrams show the IL-1 $\beta$ levels $(\mathrm{mean} \pm \mathrm{SEM}, \mathrm{n}=$ 3) measured in the rat hippocampus in the various experimental conditions, as assessed by Western blot. C: Quantification of the optical density (OD) of the IL-1 $\beta$ protein bands of $30 \mathrm{kDa}$ (pro-IL-1 $\beta$ ) and $17 \mathrm{kDa}$ (mature IL-1 $\beta$ ) normalized to the corresponding $\alpha$-actin levels (D). Data are expressed as percentage of normalized OD values measured in vehicle-treated rats. ${ }^{*} p<0.05$; ** $<<0.01$ vs. vehicle; \#p $<$ 0.01 vs. KA; IL-1 $\beta(30 \mathrm{kDa}): \mathrm{F}(3,6)=53.8$; IL-1 $\beta(17 \mathrm{kDa}): \mathrm{F}(3,10)=10.6$ by two-way ANOVA followed by Fisher test. D: Representative Western blots of pro-IL-1 $\beta(30 \mathrm{kDa})$ and mature $(17 \mathrm{kDa}) \mathrm{IL}-1 \beta$ in the rat hippocampus in the various experimental conditions. Vehicle: control rats injected with cremophor icv +PBS intrahippocampally (ih); pralnacasan: rats injected with pralnacasan $(2 \times 25 \mu \mathrm{g}$ icv, 45 and 10 min before PBS ih); KA: rats injected with cremophor icv +40 ng kainic acid ih; KA+pralnacasan: rats injected with pralnacasan $2 x$ $25 \mu \mathrm{g}$ icv, 45 and $10 \mathrm{~min}$ before kainic acid ih. All rats were killed $90 \mathrm{~min}$ after the onset of kainic acid seizures or after the injection of PBS (vehicle and pralnacasan groups). Each sample was run in duplicate (150 $\mu \mathrm{g}$ protein).

single administration ( 12.5 or $25 \mu \mathrm{g}$ in $4 \mu$ l given $45 \mathrm{~min}$ before kainic acid) or at doses $<25 \mu \mathrm{g}(12.5 \mu \mathrm{g}$ in $4 \mu \mathrm{l}$ given 45 and 10 min before kainic acid; data not shown). Pralnacasan inhibited seizure duration by $52 \%$ and $38 \%$ of control values during the first and second hour of EEG recordings, respectively, while its effect faded away during the third hour of recording. Pralnacasan did not affect spiking activity (not shown).

\section{$V X-765$}

Figure 2B shows the effect of systemic administration of VX-765 on kainic acid-induced seizures. VX-765 at doses of 25,50 , and $200 \mathrm{mg} / \mathrm{kg}$ significantly delayed the time to seizure onset by 1.5 - to twofold $(\mathrm{p}<0.01)$, reduced the number of seizures by $40 \%(\mathrm{p}<0.01)$ and the total time spent in EEG seizure activity by 30 to $50 \%$ (p < 0.01 ). No differences in spiking activity were observed (not shown).

The extent of neuronal cell loss induced by kainic acid in the CA3 area of the injected hippocampus was similar in pralnacasan- or VX-765-treated rats and their respective controls (not shown).

\section{Seizure susceptibility in caspase-1 knockout (KO) mice}

Figure 3B shows that the occurrence of seizures induced by intrahippocampal injection of $14 \mathrm{ng}$ kainic acid was significantly delayed by approximately fourfold $(\mathrm{p}<0.01)$ in caspase-1 KO mice versus their wild-type controls. The number and total time spent in seizure was reduced by $\sim 70 \%$ ( $<<0.01)$ in caspase-1 KO mice versus wild-type mice, resulting in decreased incidence of seizures during the recording period, but not in their average duration (see EEG trace in A). Spiking activity was not affected in caspase-1 KO versus wild-type mice.

Seizure onset in C57BL6/SV129 mice ( $678 \pm 71 \mathrm{~s}$ ) was significantly delayed (threefold) by pralnacasan $(25 \mu \mathrm{g}$, icv, $45 \mathrm{~min}$ and $10 \mathrm{~min}$ before kainic acid), which also reduced the duration of seizures ( $97 \pm 25 \mathrm{~s})$ in mice by $\sim 70 \%$ ( $<<0.01)$. Pralnacasan did not affect any seizure 
A

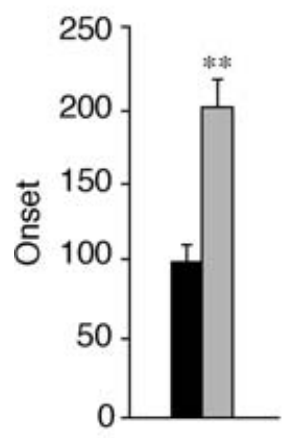

B

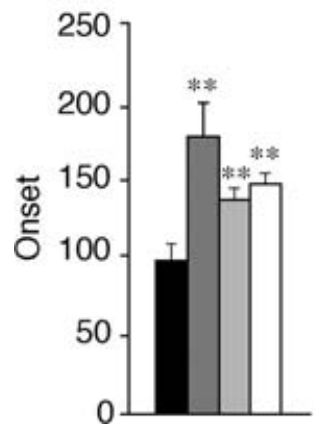

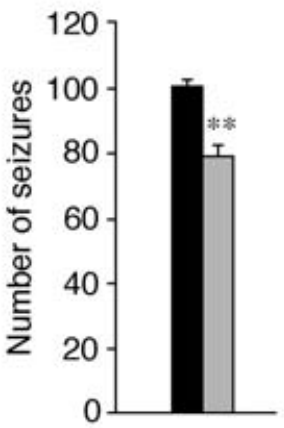
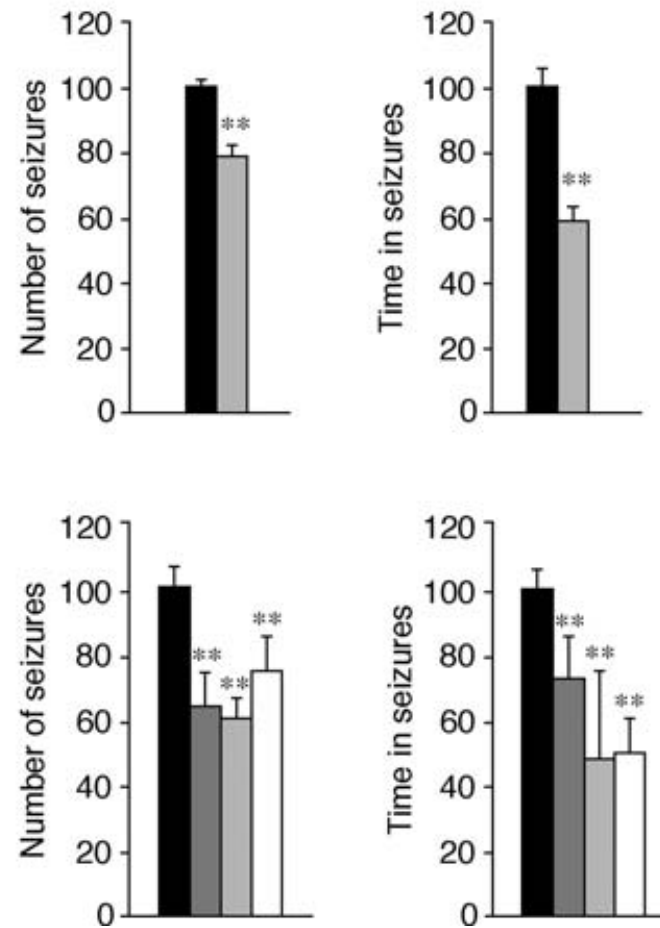

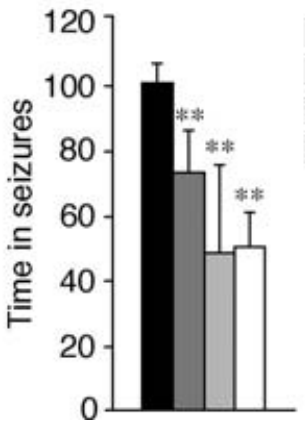

Vehicle

$\square$ Pralnacasan

FIG. 2. Effects of caspase-1 inhibition on kainic acid-induced seizures in rats A: Pralnacasan $(2 \times 25 \mu \mathrm{g}$ in $4 \mu \mathrm{l} 20 \% \mathrm{cremophor}$ in PBS, $\mathrm{n}=8$ rats) or its vehicle $(\mathrm{n}=7)$ was injected intracerebroventricularly, $45 \mathrm{~min}$ and $10 \mathrm{~min}$ before the intrahippocampal injection of $40 \mathrm{ng}$ kainic acid in $0.5 \mu \mathrm{l}$ PBS. B: VX-765 (25, 50, and $200 \mathrm{mg} / \mathrm{kg}$ dissolved in $20 \%$ cremophor in PBS, $\mathrm{n}=8$ rats in each group) or its vehicle $(n=15)$ was injected intraperitoneally for 3 consecutive days. On day 4, rats received VX-765 or vehicle, 45 min and 10 min before the intrahippocampal injection of $40 \mathrm{ng}$ kainic acid in $0.5 \mu \mathrm{l}$ PBS. EEG activity was recorded continously in freely moving rats for 30 min before (baseline) and for $180 \mathrm{~min}$ after the injection of the convulsant. Seizure parameters are defined in the Methods section. Data represent the mean \pm SEM of the various seizure parameters expressed as percentage of control values measured in vehicle-treated rats. Vehicles in pralnacsan- or VX-765-treated rats were pooled in a unique control group because they did not differ significantly [Onset (min): $7.9 \pm$ 0.7 ; Number of seizures: $32 \pm 1$; Time in seizures $(\min ): 44.0 \pm 2.0, n=22$ ]. ${ }^{* *} p<0.01$ versus vehicle by one-way ANOVA followed by Tukey's test; statistical analysis was done on absolute values.

parameter in caspase-1 KO mice, supporting that its anticonvulsant activity was specifically mediated by caspase- 1 inhibition (not shown).

\section{DISCUSSION}

The main finding of this work is that inhibition of caspase- 1 in the brain provides significant protection from acutely induced seizures in rodents. This anticonvulsive effect was achieved either after intracerebral or after systemic administration of selective caspase- 1 blockers and was associated with the ability of these drugs to prevent seizure-induced increase of the biologically active form of IL- $1 \beta$. The significant involvement of caspase1 in seizures is strongly supported by the drastic reduction in seizure susceptibility observed in mice with deletion of the caspase- 1 gene. Although wild-type and KO mice were bred separately, differences in their seizure susceptibility are unlikely because of the existence of different genetic backgrounds. Both the wild-type and KO mice originate from breeding couples of the same genetic background and derive from a similar number of genera- tions. Moreover, reported differences in seizure susceptibility to kainic acid among mouse strains $(22,23)$ concern specifically the mortality rate, behavioral seizures severity score, and neurodegeneration, and not the duration of seizures, which is the parameter significantly reduced in caspase-1 KO versus wild-type mice. Similarly, the onset to kainate-induced hippocampal EEG seizures is independent of the mouse strain as assessed in C57BL6, 129SV, and C57BL6x129SV mice (unpublished observation).

Caspase-1 inhibition or gene deletion significantly reduced ictal activity without changing interictal spiking; this effect was observed also after intrahippocampal injection of IL-1Ra or in mice overexpressing IL-1Ra in astrocytes $(6,9)$. It is possible that a reduction in IL- $1 \beta$ actions impairs the transition between interictal and ictal events, although some level of hippocampal hyperexcitability still persists. Similarly, classic AEDs such as phenytoin and carbamazepine provide seizure control without modifying interictal epileptiform activity in limbic structures (24).

The caspase- 1 gene codes for a $45-\mathrm{kDa}$ inactive precursor protein that is constitutively expressed in various cell types, including glia and neurons (25-27). This precursor 
A

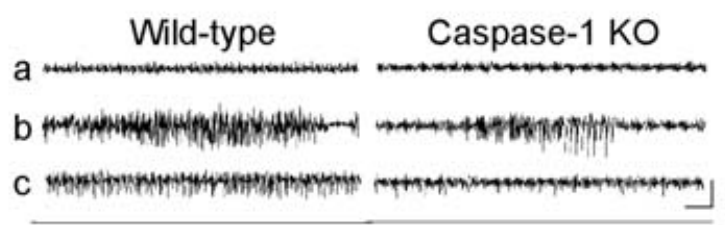

B

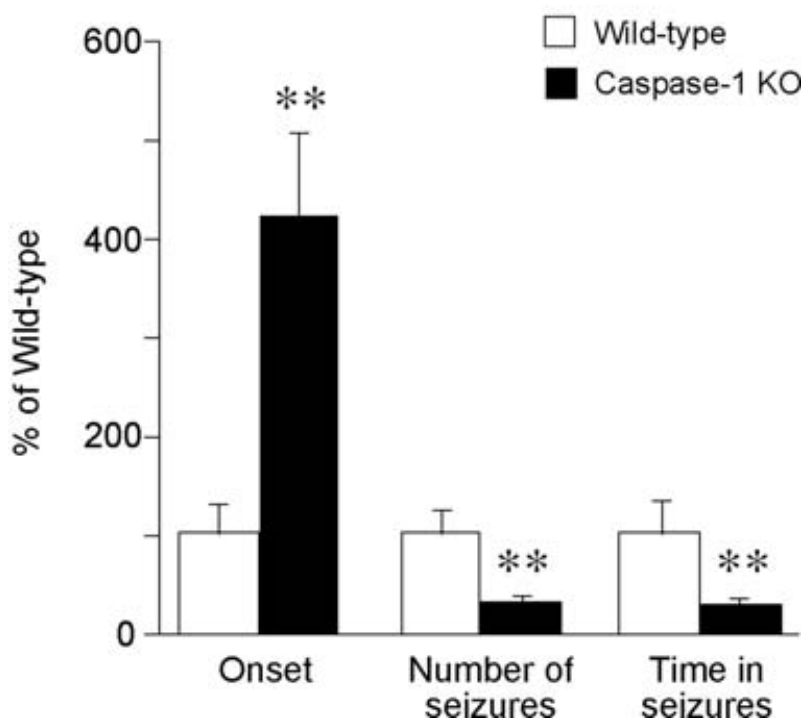

FIG. 3. Seizure susceptibility in caspase-1 knockout (KO) mice Traces in $\mathbf{A}$ represent baseline recording (a, before kainic acid injection), typical ictal episode (b) and spiking activity (c), in wildtype and caspase-1 KO mice. EEG recordings were run continuously for 180 min after convulsant injection. Horizontal bar: $5 \mathrm{~s}$. Bargrams in $\mathbf{B}$ show quantification of the EEG recordings. Data represent the mean \pm SEM $(n=8-11$ mice in each experimental group) of the various seizure parameters expressed as percentage of the respective control values. Caspase-1 KO mice and their respective controls were injected in the hippocampus unilaterally with kainic acid (14 ng) . ${ }^{*} p<0.01$ versus wild-type mice by Student's t test. Statistical analysis of data was done on absolute values.

requires two internal cleavages before becoming the enzymatically active mature enzyme. Mature caspase- 1 contributes to autoprocessing of its precursor protein by undergoing oligomerization with itself or other members of the caspase family, such as caspase-3 (28). Unlike other caspases, caspase- 1 is specifically required for processing the inactive pro-IL- $1 \beta$ and pro-IL- 18 to active IL- $1 \beta$ and IL-18, respectively (29). This process is followed by secretion of the mature cytokines from the cell through an as-yet-unknown mechanism.

In this study, pharmacologic inhibition of caspase- 1 was achieved in rodent brain by using pralnacasan or VX765 , representing a new class of protease inhibitors that specifically inhibit caspase-1. Pralnacasan is a prodrug of the potent, selective, nonpeptide competitive inhibitor RU36384, and was the first caspase-1 inhibitor to enter clinical development. VX-765 is a prodrug with improved oral bioavailability that is currently under clinical development for the treatment of inflammatory and autoimmune conditions without any ensuing signs of toxicity, as reported to date $(12,14,30)$. The powerful anticonvulsant effect achieved in rats after peripheral administration of VX-765 opens the perspective of a clinical use of selective caspase-1 inhibitors for controlling seizures.

Our biochemical evidence indicates that both pralnacasan and VX-765 blocked the release of IL- $1 \beta$ induced by activation of caspase-1 in organotypic hippocampal slice cultures, thus establishing a proof-of-concept that these drugs should block also the production and subsequent release of mature IL- $1 \beta$ in vivo. In our experimental model of seizures, we indeed found that an anticonvulsant dose of pralnacasan led to a $50 \%$ reduction in the hippocampal levels of the $17-\mathrm{kDa}$ mature form of IL- $1 \beta$ induced by seizures $(1,3,4,7,25)$. However, residual IL$1 \beta$ still remained in the hippocampus in the absence of caspase-1 activity, suggesting the existence of a pool with a slow turnover rate. Moreover, other enzymes such as matrix metalloproteinases, elastase, cathepsins, trypsin, or chymotrypsin, are able to process to some extent pro-IL$1 \beta$, and this might also be the reason for the residual IL- $1 \beta$ levels in pralnacasan-treated rats (31-33). In this respect, we found that caspase-1 inhibition does not affect CA3 pyramidal cell loss in kainate-injected rat hippocampi. It might be that the residual pool of mature IL- $1 \beta$ is sufficient to sustain kainate toxicity in spite of significant seizure reduction. Indeed, it has been reported that kainate-induced damage in CA3 depends on a direct neurotoxic action of kainate rather than on seizures per se $(34,35)$. Alternatively, kainate-induced cell loss may be insensitive to the proneurotoxic actions of IL- $1 \beta$ which have been demonstrated so far on NMDA and AMPA-mediated toxicity only (36-38)

Our findings strongly suggest that the reduction of IL$1 \beta$ levels induced by pralnacasan or VX-765 is responsible for the anticonvulsive effects of these caspase-1 inhibitors in rodents. We cannot exclude that these drugs also reduced the production of IL-18 in the brain. However, we could not detect measurable levels of this cytokine in hippocampal homogenates either in control conditions or during the acute phases of seizures.

Some antiinflammatory treatments have been shown to reduce seizures in experimental models (39-41) and in some instances in humans (42), supporting the concept that inflammation in the brain is significantly implicated in the mechanisms of hyperexcitability. Of particular interest for seizure phenomena are the functional interactions between IL- $1 \beta$ and glutamate-mediated neurotransmission. Thus IL-1 $\beta$ increases glutamate release (43), inhibits its reuptake by glia (44), and enhances NMDAmediated calcium influx into pyramidal neurons by inducing tyrosine phosphorylation of NR2B subunit (36). 
These actions anticipate a proexcitatory effect of this cytokine and support its proconvulsant actions as described in vivo $(3,4,6,10)$.

Clinical evidence linking IL- $1 \beta$ to epilepsy also exists: caspase- 1 and IL-1 are elevated in temporal lobe tissue of patients with intractable epilepsy (45-47) and a polymorphism in the promoter region of the IL- $1 \beta$ gene is associated with therapy-resistant epilepsy $(48,49)$. This polymorphism, when present in homozygotes, appears to predispose to an enhanced production of IL- $1 \beta$. Moreover, prominent inflammation in brain has been demonstrated in disease states associated with the subsequent development of intractable seizures $(50,51)$.

Because IL- $1 \beta$ exacerbates seizures and neuronal loss after various injuries, inhibits neurogenesis, and increases the blood-brain barrier permeability $(38,52-54)$, pharmacologic approaches specifically targeted to block the overproduction of IL- $1 \beta$ or its function(s) in diseased conditions may represent new, nonconventional strategies for the treatment of seizure disorders.

Acknowledgment: This work was supported by Fondazione Mariani Onlus, Milano, and Vertex Pharmaceuticals, Inc, Cambridge, MA, U.S.A. (to A.V.) and by Medical Research Council (to S.A.). Caspase-1 knockout mice were kindly supplied by Dr. W. Wong (BASF Bioresearch Corporation, Worcester, MA, U.S.A.).

\section{REFERENCES}

1. Minami M, Kuraishi Y, Satoh M. Effects of kainic acid on messenger RNA levels of IL-1 beta, IL-6, TNF alpha and LIF in the rat brain. Biochem Biophys Res Commun 1991;176:593-8.

2. Gahring LC, White HS, Skradski SL, et al. Interleukin-1alpha in the brain is induced by audiogenic seizure. Neurobiol Dis 1997;3:2639.

3. Vezzani A, Conti M, De Luigi A, et al. Interleukin-1beta immunoreactivity and microglia are enhanced in the rat hippocampus by focal kainate application: functional evidence for enhancement of electrographic seizures. J Neurosci 1999;19:5054-65.

4. De Simoni MG, Perego C, Ravizza T, et al. Inflammatory cytokines and related genes are induced in the rat hippocampus by limbic status epilepticus. Eur J Neurosci 2000;12:2623-33.

5. Plata-Salaman CR, Ilyin SE, Turrin NP, et al. Kindling modulates the IL-1beta system, TNF-alpha, TGF-beta1, and neuropeptide mRNAs in specific brain regions. Brain Res Mol Brain Res 2000;75:248-58.

6. Vezzani A, Moneta D, Conti M, et al. Powerful anticonvulsant action of IL-1 receptor antagonist on intracerebral injection and astrocytic overexpression in mice. Proc Natl Acad Sci U S A 2000;97:11534-9.

7. Oprica M, Eriksson C, Schultzberg M. Inflammatory mechanisms associated with brain damage induced by kainic acid with special reference to the interleukin-1 system. J Cell Mol Med 2003;7:12740.

8. Dinarello CA. Biologic basis for interleukin-1 in disease. Blood 1996;87:2095-147.

9. Vezzani A, Moneta D, Richichi C, et al. Functional role of inflammatory cytokines and antiinflammatory molecules in seizures and epileptogenesis. Epilepsia 2002;43(suppl 5):30-5.

10. Dube C, Vezzani A, Behrens M, et al. Interleukin-1beta contributes to the generation of experimental febrile seizures. Ann Neurol 2005;57:152-5.

11. Heida JG,Pittman QJ. Causal links between brain cytokines and experimental febrile convulsions in the rat. Epilepsia 2005;46:190613.
12. Randle JC, Harding MW, Ku G, et al. ICE/Caspase-1 inhibitors as novel anti-inflammatory drugs. Expert Opin Invest Drugs 2001;10:1207-9.

13. Leung-Toung R, Li W, Tam TF, et al. Thiol-dependent enzymes and their inhibitors: a review. Curr Med Chem 2002;9:979-1002.

14. Stack JH, Beaumont K, Larsen PD, et al. IL-converting enzyme/caspase-1 inhibitor VX-765 blocks the hypersensitive response to an inflammatory stimulus in monocytes from familial cold autoinflammatory syndrome patients. J Immunol 2005;175:2630-4.

15. Li P, Allen $\mathrm{H}$, Banerjee $\mathrm{S}$, et al. Mice deficient in IL-1 betaconverting enzyme are defective in production of mature IL-1 beta and resistant to endotoxic shock. Cell 1995;80:401-11.

16. Vezzani A, Wu HQ, Tullii M, et al. Anticonvulsant drugs effective against human temporal lobe epilepsy prevent seizures but not neurotoxicity induced in rats by quinolinic acid: electroencephalographic, behavioral and histological assessments. J Pharmacol Exp Ther 1986;239:256-63.

17. Stoppini L, Buchs PA, Muller D. A simple method for organotypic cultures of nervous tissue. J Neurosci Methods 1991;37:173-82.

18. Kristensen BW, Noraberg J, Jakobsen B, et al. Excitotoxic effects of non-NMDA receptor agonists in organotypic corticostriatal slice cultures. Brain Res 1999;841:143-59.

19. Mehta VB, Hart J, Wewers MD. ATP-stimulated release of interleukin (IL)-1beta and IL-18 requires priming by lipopolysaccharide and is independent of caspase-1 cleavage. J Biol Chem 2001;276:3820-6.

20. Dinarello CA. Interleukin-1 and interleukin-1 antagonism. Blood 1991;77:1627-52.

21. Culhane AC, Hall MD, Rothwell NJ, et al. Cloning of rat brain interleukin-18 cDNA. Mol Psychiatry 1998;3:362-6.

22. Schauwecker PE. Genetic basis of kainate-induced excitotoxicity in mice: phenotypic modulation of seizure-induced cell death. Epilepsy Res 2003;55:201-10.

23. McKhann GM 2nd, Wenzel HJ, Robbins CA, et al. Mouse strain differences in kainic acid sensitivity, seizure behavior, mortality, and hippocampal pathology. Neuroscience 2003;122:551-61.

24. Bazil CW, Pedley TA. Antiepileptic drugs. In: Mattson RH, Meldrum BS, eds. Antiepileptic drugs. New York: Raven, 1995:7989.

25. Eriksson C, Van Dam AM, Lucassen PJ, et al. Immunohistochemical localization of interleukin-1 beta, interleukin-1 receptor antagonist and interleukin-1 beta converting enzyme/caspase- 1 in the rat brain after peripheral administration of kainic acid. Neuroscience 1999;93:915-30.

26. Kim NG, Lee H, Son E, et al. Hypoxic induction of caspase11/caspase-1/interleukin-1beta in brain microglia. Brain Res Mol Brain Res 2003;114:107-14.

27. Lindberg C, Eriksson C, Van Dam AM, et al. Neuronal expression of caspase-1 immunoreactivity in the rat central nervous system. $J$ Neuroimmunol 2004;146:99-113.

28. Wilson KP, Black JA, Thomson JA, et al. Structure and mechanism of interleukin-1 beta converting enzyme. Nature 1994;370:270-5.

29. Fantuzzi G, Dinarello CA. Interleukin-18 and interleukin-1 beta: two cytokine substrates for ICE (caspase-1). J Clin Immunol 1999;19:111.

30. Siegmund B, Zeitz M. Pralnacasan (Vertex Pharmaceuticals). Drugs 2003;6:154-8.

31. Black RA, Kronheim SR, Cantrell M, et al. Generation of biologically active interleukin-1 beta by proteolytic cleavage of the inactive precursor. J Biol Chem 1988;263:9437-42.

32. Hazuda DJ, Strickler J, Kueppers F, et al. Processing of precursor interleukin 1 beta and inflammatory disease. J Biol Chem 1990;265:6318-22.

33. Schonbeck U, Mach F, Libby P. Generation of biologically active IL1 beta by matrix metalloproteinases: a novel caspase-1-independent pathway of IL-1 beta processing. J Immunol 1998;161:3340-6.

34. Fariello RG, Golden GT, Smith GG, et al. Potentiation of kainic acid epileptogenicity and sparing from neuronal damage by an NMDA receptor antagonist. Epilepsy Res 1989;3:206-13.

35. Jarrard LE. Use of excitotoxins to lesion the hippocampus: update. Hippocampus 2002;12:405-14.

36. Viviani B, Bartesaghi S, Gardoni F, et al. Interleukin-1beta enhances 
NMDA receptor-mediated intracellular calcium increase through activation of the Src family of kinases. J Neurosci 2003;23:8692700.

37. Bernardino L, Xapelli S, Silva AP, et al. Modulator effects of interleukin 1beta and tumor necrosis factor-alpha on AMPA-induced excitotoxicity in mouse organotypic hippocampal slice cultures. $J$ Neurosci 2005;25:6734-44.

38. Allan SM, Tyrrell PJ, Rothwell NJ. Interleukin-1 and neuronal injury. Nat Rev Immunol 2005;5:629-40.

39. Wallenstein MC. Attenuation of penicillin models of epilepsy by nonsteroidal anti-inflammatory drugs. Exp Neurol 1987;98:15260.

40. Srivastava AK, Gupta YK. Aspirin modulates the anticonvulsant effect of diazepam and sodium valproate in pentylenetetrazole and maximal electroshock induced seizures in mice. Indian J Physiol Pharmacol 2001;45:475-80.

41. Sayyah M, Javad-Pour M, Ghazi-Khansari M. The bacterial endotoxin lipopolysaccharide enhances seizure susceptibility in mice: involvement of proinflammatory factors: nitric oxide and prostaglandins. Neuroscience 2003;122:1073-80.

42. Vezzani A, Granata T. Brain inflammation in epilepsy: experimental and clinical evidence. Epilepsia 2005;46:1724-43.

43. Kamikawa H, Hori T, Nakane H, et al. IL-1beta increases norepinephrine level in rat frontal cortex: involvement of prostanoids, NO, and glutamate. Am J Physiol 1998;275:R803-10.

44. Ye ZC, Sontheimer H. Cytokine modulation of glial glutamate uptake: a possible involvement of nitric oxide. Neuroreport 1996;7:2181-5.

45. Sheng JG, Boop FA, Mrak RE, et al. Increased neuronal betaamyloid precursor protein expression in human temporal lobe epilepsy: association with interleukin-1 alpha immunoreactivity. $J$ Neurochem 1994;63:1872-9.

46. Henshall DC, Clark RS, Adelson PD, et al. Alterations in bcl-2 and caspase gene family protein expression in human temporal lobe epilepsy. Neurology 2000;55:250-7.

47. Ravizza T, Boer K, Redeker S, et al. The IL-1beta system in epilepsyassociated malformations of cortical development. Neurobiol Dis in press.

48. Kanemoto K, Kawasaki J, Miyamoto T, et al. Interleukin (IL)1 beta, IL-1alpha, and IL-1 receptor antagonist gene polymorphisms in patients with temporal lobe epilepsy. Ann Neurol 2000;47:571-4.

49. Virta M, Hurme M, Helminen M. Increased frequency of interleukin1 beta (-511) allele 2 in febrile seizures. Pediatr Neurol 2002;26:1925 .

50. Baranzini SE, Laxer K, Bollen A, et al. Gene expression analysis reveals altered brain transcription of glutamate receptors and inflammatory genes in a patient with chronic focal (Rasmussen's) encephalitis. J Neuroimmunol 2002;128:9-15.

51. Maldonado M, Baybis M, Newman D, et al. Expression of ICAM-1, TNF-alpha, NF kappa B, and MAP kinase in tubers of the tuberous sclerosis complex. Neurobiol Dis 2003;14:279-90.

52. Quagliarello VJ, Wispelwey B, Long WJ Jr, et al. Recombinant human interleukin-1 induces meningitis and blood-brain barrier injury in the rat: characterization and comparison with tumor necrosis factor. J Clin Invest 1991;87:1360-6.

53. Ekdahl CT, Claasen JH, Bonde $\mathrm{S}$, et al. Inflammation is detrimental for neurogenesis in adult brain. Proc Natl Acad Sci U S A 2003;100:13632-7.

54. Monje ML, Toda H, Palmer TD. Inflammatory blockade restores adult hippocampal neurogenesis. Science 2003;302:1760-5. 